\title{
Medication Use in the Community: Comparison between Urban and Rural Home Pharmacies
}

\author{
Mina Maričić, M.D. ${ }^{1}$, Milica Paut Kusturica, MPharm, Ph.D. ${ }^{2}$, Mia Manojlović, M.D. ${ }^{1}$, \\ Ana Tomas, M.D. ${ }^{2}$, Olga Horvat, M.D., Ph.D², Svetlana Goločorbin Kon, MPharm., Ph.D. ${ }^{3}$, \\ Zdenko Tomić, M.D., Ph.D. ${ }^{2}$, Ana Sabo, M.D., Ph.D. ${ }^{2}$
}

${ }^{1}$ Faculty of Medicine, ${ }^{2}$ Department of Pharmacology and Toxicology, ${ }^{3}$ Department of Pharmacy, Faculty of Medicine, University of Novi Sad, Vojvodina, Novi Sad 21000, Serbia.

Received 18 December 2018 • Revised 29 March 2019 • Accepted 3 April 2019 • Published online 7 June 2019

\section{Abstract:}

Objective: This study aimed to examine the contents of home pharmacies and medication use, as well as storage and disposal habits in urban and rural households in Serbia.

Material and Methods: This prospective research was conducted within 70 households in Novi Sad (urban setting) and Laćarak (rural setting) from October 1, 2015 to January 15, 2016. The data were collected using a standardized questionnaire, as well as by direct examination of drugs stored in households.

Results: The most common groups of drugs stored were cardiovascular drugs, drugs for the nervous system, antirheumatic products and antimicrobials. A high percentage of drugs for the alimentary tract were found stored in Laćarak, while drugs for the respiratory tract were discovered in Novi Sad. Prescription only medications (POMs) made up 69.7\% of all medications in Laćarak and 60.6\% in Novi Sad. POMs were purchased independently in high amounts (13.2\% in Laćarak and $9.1 \%$ in Novi Sad). Presence of expired medications was higher in Laćarak (12.0\%) than Novi Sad (5.8\%). Over two-thirds of the households stored medications properly; however, only $10.0 \%$ of respondents reported the proper disposal of unused medications.

Conclusion: The structures of home pharmacies in Novi Sad and Laćarak differ, which implies different healthcare needs. The practice of self-medicating was noted both in Novi Sad and Laćarak. While Laćarak residents rely more on the advice of friends and family, Novi Sad residents buy medicine mostly without any consultation. Medications in both environments are stored properly in the majority of households, but mostly disposed of improperly together with household waste.

Keywords: consumer safety; expiration date; self-medication; storage and disposal

Contact: Ana Tomas, M.D

Department of Pharmacology and Toxicology, Faculty of Medicine,

University of Novi Sad, Vojvodina, Novi Sad 21000, Serbia.

E-mail: aanaa_tomas@yahoo.com;ana.tomas@mf.uns.ac.rs
J Health Sci Med Res 2019;37(3):197-206 doi: 10.31584/jhsmr.201953 www.jhsmr.org 


\section{Introduction}

Use of medicine is influenced by socioeconomic and cultural factors, education and availability. Based on the medicines found in households, as well as the knowledge and attitudes of family members, it is possible to examine how much people rely on self-medication, the drugs which are most often used without consultation, to what extent they adhere to the prescribed dosage regimens, and whether they are familiar with the conditions for proper storage and disposal of drugs. ${ }^{1}$ The reaction to the presence of certain clinical symptoms is determined by different circumstances, but a significant number of people will not seek medical help until the symptoms significantly worsen or become an obstacle to everyday activities. ${ }^{2,3}$ Over-the-counter medicines (OTC), as well as prescription-only medicines (POMs), can be found in households. A large selection of OTC drugs provides the possibility of free choice in self-medication. Drug advertising should be objective, and mustn't lead to wrong conclusions, or warrant that drug safety and efficacy is ensured by its natural origin. ${ }^{4}$ In practice, everywhere in the world, such regulations, as well as many other ethical principles, are violated in a sophisticated way. ${ }^{5}$ In countries in transition, such as Serbia, the inaccessibility of the healthcare system, due to large crowds in health centers, lack of time due to the fast paced modern lifestyle, as well as the high prices of treatment in private practice, causes a lot of people to choose self-medication. ${ }^{6}$ Although self-medication as a treatment method reduces pressure on the healthcare system, and can be useful if patients have an adequate level of knowledge and if they use only OTC medicines, ${ }^{1}$ it still contains the risk of improper treatment and more frequent adverse effects, which then burden healthcare services with additional costs. ${ }^{7}$ In particular, it is necessary to restrict self-medication in certain populations, such as pregnant women, breastfeeding mothers, children, and people older than 65 years due to age- related metabolic and excretion function involvement. ${ }^{8}$ Besides OTC drugs, it appears that POMs are often used by people on their own initiative, if pharmacies and employees do not adhere to the regulations. ${ }^{9,10}$ Although drug storage in households is a common practice, it can pose a health risk, especially if medicines are not stored in accordance with the manufacturer's instructions. Pharmacy staff members usually offer only instructions concerning the drug delivery process, while information about proper storage of medicines in households is usually omitted. ${ }^{11}$ Not every place in a home is suitable for drug storage. Storing drugs in the kitchen or bathroom can lead to their exposure to moisture and high temperatures, which can shorten the expiry date. It is important to note that some drugs are photodegradable, and thus light exposure may result in potency loss, altered efficacy, and adverse biological effects. ${ }^{1}$ Further, storing drugs in reachable places carries the risk of intoxication, especially in families with young children. ${ }^{12-14}$ Drug compliance depends on many factors, and the most common reasons for noncompliance are forgetting, adverse effects, changes to the dose or regimen by the physician, health improvement, and lack of insight into treatment benefits. ${ }^{15}$ In households, we can find expired stored medicines and leftover medicines. It is also necessary to point out the importance of proper drug disposal, because drugs thrown in the trash together with domestic waste or in the sewerage system pollute our environment. Drugs reach landfills, rivers and the water supply, which results in antimicrobial's resistance, use of expensive reserve antibiotics, and the exposure of the population to mutagens and allergens. ${ }^{16}$ Drug manufacturers and vendors are obliged to organize drug destruction; however, this policy has not yet been fully implemented in practice. ${ }^{17}$

A study conducted in 2012 in Novi Sad ${ }^{7}$ noted the differences in home pharmacies between urban and suburban households, raising the need for examining the 
differences in medication storage, use, and disposal in different socio-demographic settings. Examination and comparison of the drug inventories between households in urban and rural setting provides information about the similarities and differences of the burden of health disorders in the population of urban and rural environments in Vojvodina. Secondly, knowing that self-medication, especially with POMs, can lead to unfavorable medical consequences, and that this type of treatment in Serbia has been on the rise, it was necessary to examine the adherence to the enforcement of the law restricting the purchase of numerous drugs without medical prescription several years after adoption, in order to make clear where any further action is required. Drug disposal habits in households was also a topic of great interest, considering the unregulated system of disposal in Serbia, and the substantial ecological consequences of improper drug disposal, as well as the data gained through this study which could lead to a possible solution. Therefore, this study was designed to examine the contents and to compare the structures of home pharmacies in urban and rural environments. Additionally, the aim was to investigate the attitudes and habits with regard to self-medication, drug storage, and disposal habits.

\section{Material and Methods}

This cross-sectional study was conducted in households from October $1^{\text {th }}, 2015$ to January $15^{\text {th }} 2016$. The study includes households in the municipality of Novi Sad, the largest city in Vojvodina, and households from Laćarak, the largest village in Vojvodina. The study was approved by the Ethics Committee of the Faculty of Medicine in Novi Sad (approval number: 01-3385/1). The researchers employed a snowball recruitment method. The study was revealed to different acquaintances in order to recruit the first participating household. Afterwards, the respondents were asked to recommend the next household for possible inclusion in the study through their social contacts. The respondent (family member $>18$ years of age) was informed of the details of the study through a telephone conversation. All respondents signed an informed consent form before joining the research. During visits, we conducted reviews and analyses of all drugs in the household (trade name, pharmaceutical formulation, expiry date, presence of secondary packaging, presence of summary of product characteristics, number of pills in a package). For every drug item the respondents answered the following questions: indication for what the drug is/was used, method of obtaining the drug (voluntarily purchased in a pharmacy, obtained from friends and family or issued on prescription) and whether the drug was currently being used (current use was defined as used 10 days prior to the interview).

After recording all the drugs in the household, respondents completed the questionnaire. The first part of the questionnaire was related to the socio-demographic characteristics of the household, while the second part referred to storage and disposal habits. After the data had been collected, drugs were classified according to the Anatomical Therapeutic Chemical (ATC) Classification System. The data was processed in Excel 2016 and Statistical Package for the Social Sciences (SPSS) software (SPSS 15.0 for Windows, SPSS Inc., Chicago, IL, USA). Results were presented as a frequency, percentage, mean and standard deviation. The chisquared test for nominal variables was used to compare the differences between the rural and urban households. All $p$-values less than 0.05 were considered significant.

\section{Results}

In this study, we analyzed a total of 70 households, 35 in the municipality of Novi Sad and 35 in Laćarak. Total number of drug items present in households was 508 drugs (241 in Novi Sad and 267 in Laćarak). There 
was no difference in household size between Novi Sad (3.6 \pm 1.3 members per household) and Laćarak (3.5 \pm 1.6 members per household). The average number of drug items per households was significantly higher in Laćarak $(7.6 \pm 4.5)$ than in Novi Sad $(6.9 \pm 3.6)$, (p-value=0.04).

Table 1 shows the main groups of drugs ( $1^{\text {st }}$ levels) according to ATC classification. The most commonly used drugs in Novi Sad belonged to the nervous system, followed by the Musculo-skeletal system, cardiovascular system, antiinfectives for systemic use, and the respiratory system drug group.

Table 2 shows the most common subgroups of drugs $\left(2^{\text {nd }}\right.$ levels) within the most frequently present groups of drugs in the households. Within the nervous system drug group, the most common drugs were analgesics (N02). Analgesics were more common in Novi Sad (19.1\%) in comparison to Laćarak (7.1\%). Psycholeptics (N05) and psychoanaleptics (N06) were more common in Laćarak. The most common subgroup of cardiovascular system drugs in both places was agents acting on the rennin-angiotensin system (C09), while the most common drugs in the musculo-skeletal system drug group in both environments were antiinflammatory and antirheumatic products (M01). Within the alimentary tract and metabolism drug group, the most common drugs in Laćarak were drugs for functional gastrointestinal disorders (A03), antidiarrheals, and intestinal antiinflammatory/antiinfective agents (A07), while the most common drugs in Novi Sad within the same drug group were drugs for acid related disorders (A02) and drugs used in diabetes (A10). A majority of the drugs within the antiinfectives for systemic use drug group were antibacterials for systemic use (J01) in both settings.

Table 3 shows drugs in households according to the mode of issuance. There were more POMs in Laćarak $(69.7 \%)$ compared to Novi Sad $(60.6 \%)$, (p-value<0.01).

Table 1 Structure of home pharmacies (Anatomical Therapeutic Chemical classification- $1^{\text {st }}$ levels)

\begin{tabular}{|c|c|c|c|c|c|c|}
\hline \multirow{3}{*}{ Anatomical Therapeutic Chemical classification } & \multicolumn{6}{|c|}{ Place of residence } \\
\hline & \multicolumn{2}{|c|}{ Laćarak } & \multicolumn{2}{|c|}{ Novi Sad } & \multicolumn{2}{|c|}{ Total } \\
\hline & Number* & $\%$ & Number* & $\%$ & Number* & $\%$ \\
\hline Alimentary tract and metabolism & 39 & 14.6 & 28 & 11.6 & 67 & 13.2 \\
\hline Blood and blood forming organs & 13 & 4.9 & 4 & 1.7 & 17 & 3.4 \\
\hline Cardiovascular system & 64 & 24.0 & 29 & 12.0 & 93 & 18.3 \\
\hline Dermatologicals & 11 & 4.1 & 14 & 5.8 & 25 & 4.9 \\
\hline Antiinfectives for systemic use & 25 & 9.4 & 29 & 12.0 & 54 & 10.6 \\
\hline Musculo-skeletal system & 45 & 16.9 & 40 & 16.6 & 85 & 16.7 \\
\hline Nervous system & 39 & 14.6 & 55 & 22.8 & 94 & 18.5 \\
\hline Respiratory system & 18 & 6.7 & 22 & 9.1 & 40 & 7.9 \\
\hline Various & 13 & 4.9 & 20 & 8.3 & 33 & 6.5 \\
\hline Total & 267 & 100.0 & 241 & 100.0 & 508 & 100.0 \\
\hline
\end{tabular}

*number of drug items 
Table 2 Five most common groups of drugs in households (Anatomical Therapeutic Chemical Classification $-2^{\text {nd }}$ levels)

\begin{tabular}{|c|c|c|c|c|}
\hline \multirow{3}{*}{ Anatomical Therapeutic Chemical classification } & \multicolumn{4}{|c|}{ Place of residence } \\
\hline & \multicolumn{2}{|c|}{ Laćarak } & \multicolumn{2}{|c|}{ Novi Sad } \\
\hline & Number* & $\%$ & Number* & $\%$ \\
\hline N-Nervous system & 39 & 14.6 & 55 & 22.8 \\
\hline N02-Analgesics & 19 & 7.1 & 46 & 19.1 \\
\hline N03-Antiepileptics & 1 & 0.4 & 1 & 0.4 \\
\hline N04-Anti-Parkinson drugs & 3 & 1.1 & 0 & 0.0 \\
\hline N05-Psycholeptics & 11 & 4.1 & 6 & 2.5 \\
\hline N06-Psychoanaleptics & 5 & 1.9 & 1 & 0.4 \\
\hline N07-Other nervous system drugs & 0 & 0.0 & 1 & 0.4 \\
\hline C-Cardiovaskular system & 64 & 24.0 & 29 & 12.0 \\
\hline C01-Cardiac therapy & 0 & 0.0 & 1 & 0.4 \\
\hline C02-Antihypertensives & 1 & 0.4 & 1 & 0.4 \\
\hline C03-Diuretics & 7 & 2.6 & 2 & 0.8 \\
\hline C04-Peripheral vasodilators & 2 & 0.8 & 0 & 0.0 \\
\hline C05-Vasoprotectives & 4 & 1.5 & 8 & 3.3 \\
\hline C07-Beta blocking agents & 12 & 4.5 & 7 & 2.9 \\
\hline C08-Calcium channel blockers & 12 & 4.5 & 0 & 0.0 \\
\hline C09-Agents acting on the rennin-angiotensin system & 24 & 9.0 & 9 & 3.7 \\
\hline C10-Lipid modifying agents & 2 & 0.8 & 1 & 0.4 \\
\hline M-Musculo-skeletal system & 45 & 16.9 & 40 & 16.6 \\
\hline M01-Antiinflammatory and antirreumatic products & 41 & 15.4 & 36 & 14.9 \\
\hline M02-Topical products for joints and muscular pain & 4 & 1.5 & 4 & 1.7 \\
\hline A-Alimentary tract and metabolism & 39 & 14.6 & 28 & 11.6 \\
\hline A01-Stomatological preparations & 5 & 1.9 & 4 & 1.7 \\
\hline A02-Drugs for acid related disorders & 4 & 1.5 & 10 & 4.2 \\
\hline A03-Drugs for functional gastrointestinal disorders & 6 & 2.3 & 2 & 0.8 \\
\hline A06-Drugs for constipation & 2 & 0.8 & 0 & 0.0 \\
\hline A07-Antidiarrheals, intestinal antiinflammatory/antiinfectiveagents & 12 & 4.5 & 3 & 1.2 \\
\hline A10-Drugs used in diabetes & 5 & 1.9 & 8 & 3.3 \\
\hline A11-Vitamins & 5 & 1.9 & 1 & 0.4 \\
\hline J-Antiinfectives for systemic use & 25 & 9.4 & 29 & 12.0 \\
\hline J01-Antibacterials for systemic use & 23 & 8.6 & 28 & 11.3 \\
\hline J02-Antimycotics for systemic use & 1 & 0.4 & 0 & 0.0 \\
\hline J04-Antimycobacterials & 1 & 0.4 & 1 & 0.4 \\
\hline Other & 55 & 20.6 & 60 & 24.9 \\
\hline Total & 267 & 100.0 & 241 & 100.0 \\
\hline
\end{tabular}

*number of drug items 
Data on the method of drug purchase did not match the data on the drug issuance mode. Out of a total number of drugs, $13.1 \%$ in Laćarak and $9.1 \%$ in Novi Sad were POMs purchased without prescription or obtained from friends or family. More respondents from Novi Sad acquired POMs independently compared to respondents from Laćarak, while more respondents from Laćarak obtained POMs from friends and family compared to respondents from Novi Sad (Table 4).

In both settings drugs were usually stored in one place in the household. Mostly drugs were found in living rooms and bedrooms, although in a high percentage of households in Laćarak (28.6\%), as well as households in Novi Sad (22.9\%), drugs were also found stored in the kitchen. In $2.9 \%$ of the households of Laćarak and $11.4 \%$ of the households of Novi Sad, drugs were stored in the bathroom. Drug items were kept in hard to access places for children in just $20 \%$ of households in Laćarak but in more than $66.6 \%$ of households in Novi Sad, which was a significant difference $(p-v a l u e<0.01)$. We found more drugs which were not in current use in households in Novi Sad $(54.8 \%)$, in comparison to Laćarak $(40.8 \%)$, (p-value= 0.034). Expired drugs made up $12 \%$ of all the drugs in Laćarak and $5.8 \%$ of all the drugs in Novi Sad (p-value< 0.01). Unused drugs were usually disposed of with home waste (Laćarak - 71.4\%, Novi Sad - 74.3\%), while a small percentage of unused drugs were handed over to a pharmacy (Table 5).

Table 3 Drugs in households according to the mode of issuance

\begin{tabular}{|c|c|c|c|c|c|c|c|}
\hline \multirow{3}{*}{ Variable } & \multicolumn{6}{|c|}{ Place of residence } & \multirow{3}{*}{$\begin{array}{l}\text { Chi-squared } \\
\text { p-value }\end{array}$} \\
\hline & \multicolumn{2}{|c|}{ Laćarak } & \multicolumn{2}{|c|}{ Novi Sad } & \multicolumn{2}{|c|}{ Total } & \\
\hline & Number* & $\%$ & Number* & $\%$ & Number* & $\%$ & \\
\hline Mode of drug issuance & & & & & & & $<0.01$ \\
\hline Over-the-counter & 81 & 30.3 & 95 & 39.4 & 176 & 34.6 & \\
\hline Prescription-only-medication & 186 & 69.7 & 146 & 60.6 & 332 & 65.4 & \\
\hline Total & 267 & 100.0 & 241 & 100.0 & 508 & 100.0 & \\
\hline
\end{tabular}

*number of drug items

Table 4 Drugs in households according to the obtaining manner

\begin{tabular}{|c|c|c|c|c|c|c|c|}
\hline \multirow{3}{*}{ Variable } & \multicolumn{6}{|c|}{ Place of residence } & \multirow{3}{*}{$\begin{array}{l}\text { Chi-squared } \\
\text { p-value }\end{array}$} \\
\hline & \multicolumn{2}{|c|}{ Laćarak } & \multicolumn{2}{|c|}{ Novi Sad } & \multicolumn{2}{|c|}{ Total } & \\
\hline & Number* & $\%$ & Number* & $\%$ & Number* & $\%$ & \\
\hline Purchase method & & & & & & & 0.96 \\
\hline Acquired with prescription & 151 & 56.6 & 124 & 51.5 & 275 & 54.1 & \\
\hline Obtained from friends or family & 27 & 10.1 & 14 & 5.8 & 41 & 8.1 & \\
\hline Purchased without prescription & 89 & 33.3 & 103 & 42.7 & 192 & 37.8 & \\
\hline Total & 267 & 100.0 & 241 & 100.0 & 508 & 100.0 & \\
\hline
\end{tabular}

*number of drug items 
Table 5 Storage and disposal of drugs in households

\begin{tabular}{|c|c|c|c|c|c|c|c|}
\hline \multirow{3}{*}{ Variable } & \multicolumn{6}{|c|}{ Place of residence } & \multirow{3}{*}{$\begin{array}{l}\text { Chi-squared } \\
\text { p-value }\end{array}$} \\
\hline & \multicolumn{2}{|c|}{ Laćarak } & \multicolumn{2}{|c|}{ Novi Sad } & \multicolumn{2}{|c|}{ Total } & \\
\hline & Number & $\%$ & Number & $\%$ & Number & $\%$ & \\
\hline Drug storage & $\mathrm{N}^{* *}$ & & $\mathrm{~N}^{* *}$ & & $\mathrm{~N}^{* *}$ & & $<0.01$ \\
\hline In one place in household & 18 & 51.4 & 23 & 65.7 & 41 & 58.6 & \\
\hline In more places & 17 & 48.6 & 12 & 34.3 & 18 & 41.5 & \\
\hline Total & 35 & 100.0 & 35 & 100.0 & 70 & 100.0 & \\
\hline Drug storing room & $\mathrm{N}^{\star \star}$ & & $\mathrm{N}^{\star *}$ & & $\mathrm{~N}^{* *}$ & & 0.06 \\
\hline Living room & 10 & 28.6 & 12 & 34.3 & 22 & 31.5 & \\
\hline Kitchen & 10 & 28.6 & 8 & 22.9 & 18 & 25.8 & \\
\hline Bathroom & 1 & 2.9 & 4 & 11.4 & 5 & 7.2 & \\
\hline Pantry & 1 & 2.9 & 4 & 11.4 & 5 & 7.2 & \\
\hline Bedroom & 13 & 37.1 & 7 & 20.0 & 20 & 28.6 & \\
\hline Total & 35 & 100.0 & 35 & 100.0 & 70 & 100.0 & \\
\hline Drug used for & $\mathrm{N}^{*}$ & & $\mathrm{~N}^{*}$ & & $\mathrm{~N}^{*}$ & & $<0.001$ \\
\hline Acute disease & 30 & 11.3 & 45 & 18.7 & 75 & 14.8 & \\
\hline Chronic disease & 128 & 47.9 & 64 & 26.6 & 192 & 37.8 & \\
\hline Not in current use & 109 & 40.8 & 132 & 54.8 & 241 & 47.4 & \\
\hline Total & 267 & 100.0 & 241 & 100.0 & 508 & 100.0 & \\
\hline Expired medication & $\mathrm{N}^{*}$ & & $\mathrm{~N}^{*}$ & & $\mathrm{~N}^{*}$ & & 0.015 \\
\hline Expired & 32 & 12.0 & 14 & 5.8 & 46 & 9.1 & \\
\hline Not expired & 235 & 88.0 & 227 & 94.2 & 462 & 90.9 & \\
\hline Total & 267 & 100.0 & 241 & 100.0 & 508 & 100.0 & \\
\hline Accessibility to children & $\mathrm{N}^{* *}$ & & $\mathrm{~N}^{* *}$ & & $\mathrm{~N}^{* *}$ & & 0.01 \\
\hline Easily accessible & 8 & 80.0 & 4 & 33.3 & 12 & 54.6 & \\
\hline Hardly accessible & 2 & 20.0 & 8 & 66.6 & 10 & 45.4 & \\
\hline Total & 10 & 100.0 & 12 & 100.0 & 22 & 100.0 & \\
\hline Drug disposal & $\mathrm{N}^{\star *}$ & & $\mathrm{~N}^{\star *}$ & & $\mathrm{~N}^{* *}$ & & 0.305 \\
\hline Together with home waste & 25 & 71.4 & 26 & 74.3 & 51 & 54.3 & \\
\hline Hand over to pharmacy & 4 & 11.4 & 3 & 8.6 & 7 & 10.0 & \\
\hline Burn & 3 & 8.6 & 2 & 5.7 & 5 & 7.2 & \\
\hline Pass on to friends/family & 2 & 5.7 & 0 & 0.0 & 2 & 2.8 & \\
\hline Other & 1 & 2.9 & 4 & 11.4 & 5 & 6.6 & \\
\hline Total & 35 & 100.0 & 35 & 100.0 & 70 & 100.0 & \\
\hline
\end{tabular}

$\mathrm{N}^{*}=$ number of drug items, $\mathrm{N}^{* *}=$ number of households

Data for accessibility to children included only households with children $<12$ years of age 


\section{Discussion}

During the analysis of the drugs in households in Novi Sad and Laćarak, we examined similarities and differences in amount and structure of drugs in urban and suburban households. Also, we gained insight into different aspects of drug usage, such as self-medication practice, storage, and disposal of unused medicines. Our research has shown that there were certain differences in the drugs stored in the households of Novi Sad and Laćarak. A higher percentage of drugs acting on the respiratory system were found in Novi Sad. This could be explained by poorer air quality in an urban environment. We found more drugs acting on the cardiovascular system and alimentary tract and metabolism (primarily drugs for functional gastrointestinal disorders and antidiarrheals) in Laćarak, compared to Novi Sad, which can be related to traditional eating habits in the southern part of Srem (where Laćarak is located), which abounds with meat products and alcoholic beverages; and, it is an average elderly population living in the countryside. More drugs for acid-related disorders were found in Novi Sad. This can be explained by its contemporary urban lifestyle and consequent psychological stress.

Results of our study show a higher percentage of OTC drugs in the households of Novi Sad (39.4\%) compared to Laćarak (30.3\%), which can be explained by a younger population in the urban environment, which mainly uses modern communication means and information sources. Almost identical results in Novi Sad were obtained by Paut Kusturica and colleagues (41.0\%): OTC drugs were the majority of drugs found in the households of Novi Sad). ${ }^{6}$ Despite the efforts made to improve the control of POM dispensing and use in Serbia through the enforcement of laws restricting the purchase of many drugs, especially antibiotics, without medical prescriptions (November 2011), this still remains a serious issue. ${ }^{4}$ The Medicines and Medical Devices Agency of Serbia performs the classification of medicinal products, regulates the regime of their dispensing, and publishes a list of around 300 drugs that are available OTC. However, there is a discrepancy between legislation and everyday practice. Out of all the drugs in households of Laćarak, $13.1 \%$ were POMs purchased independently without a prescription. POMs purchased without a prescription in Novi Sad made up $9.1 \%$ of the total number of found drugs. A study from 2012, conducted in Novi Sad showed that $21 \%$ of total drugs found were POMs obtained without prescription ${ }^{6}$, which is a favorable time trend, bearing in mind that the existing legislation and stricter controls didn't start until November 2011, and time was required for the implementation of these regulations. Differences in obtaining POMs between the urban and rural environment could be explained by more frequent controls in pharmacies in the urban environments, and closer social contacts and trust among the inhabitants of the rural environments. In addition, our results showed that a higher number of Laćarak residents purchased medications, advised by friends and family members or received unused medicines through social contacts, compared to Novi Sad. A study conducted in Belgium in 2008 by Bello and colleagues in households in both urban and rural settings, but disregarding comparison, showed that $21.0 \%$ of all drug packages found were POMs purchased without prescription. $^{18}$

Almost two-thirds of the respondents in both environments stored medicines in places that are considered suitable for drug storage, ie, the living room and bedroom. One-third of the respondents in both environments, however, stored drugs in the kitchen and bathroom, exposing them to humidity, temperature changes, chemicals, and food. Two-thirds of respondents stored drugs properly, far less compared with respondents from Belgian households (89.5\%). ${ }^{18}$ Emphasizing proper drug storage habits and the consequences of improper storage 
by pharmacists in pharmacies is of essential importance. In $80.0 \%$ of households in Laćarak and $33.3 \%$ in Novi Sad, drugs were stored in places easily accessible to children. Our results differ from those obtained in the study from $2010^{17}$, when availability of drugs for children was $20.0 \%$ in Novi Sad and $23.0 \%$ in households in the rural areas around Novi Sad. Thus, there remains the question of whether habits have significantly changed in this period or this topic requires more data obtained from a larger sample. Results from a study conducted in Croatia in both rural and urban households showed that in $36.0 \%$ of households drugs were kept within the reach of children. ${ }^{19}$ One of the most serious consequences of preserving drugs in accessible places may be child intoxication. The World Health Organization points out that drug poisoning is most common in the age group 1-4, while the second peak of incidence of drug poisoning (most often on purpose) is in the age group $15-16^{20}$; therefore, it is of the utmost importance to turn public attention to the possible serious consequences of drug availability in regard to children. Our results showed that the percentage of expired drugs was twice as high in the analyzed rural environment (12.0\%) compared to the urban (5.8\%). This percentage of expired drugs in the households of Novi Sad was lower compared to the research from $2014(9.2 \%)^{1}, 2008(12.0 \%)^{7}$ and 1996 $(7.0 \%) .{ }^{21}$ The percentage of expired drugs in both settings in our research was lower when compared with Belgian households where $21.0 \%$ of drug packages had passed their expiration date. ${ }^{18}$ Our results showed that $88.6 \%$ of Laćarak residents and $91.4 \%$ of Novi Sad residents disposed of unused drugs improperly, usually together with household waste. As reasons they stated: that was the easiest way to dispose of the drugs, they did not know the proper manner or that the pharmacy staff had refused to take the drugs to be destroyed in a proper manner. Results obtained in a study from $2010^{17}$ showed that $85.0 \%$ of residents in urban and $75.0 \%$ in rural areas had improper drug disposal habits. Results showed that $11.4 \%$ of Laćarak residents and $8.6 \%$ of Novi Sad residents handed over unused medicines to the pharmacy. Improperly disposing of unused drugs together with domestic waste, or in the sewage system, endangers our environment. This way, drugs reach lands, water and the living world, leading to bioaccumulation and directly influence the living world, including humans, due to antimicrobials, hormones and cytostatic agents, which leads to antimicrobial resistance, and changes in genotype and phenotype. ${ }^{22}$ In accordance with the regulations of the Republic of Serbia, pharmacies are obliged to collect pharmaceutical waste from citizens, but the core of the problem is that the regulations don't define strictly who will take the financial responsibility of disposal, wholesalers or drug manufacturers. Thus, there is no effective system of destroying pharmaceutical waste. Pharmacies do not promote and encourage patients to return unused medicines to pharmacies. ${ }^{1}$

Our study had certain limitations that need to be mentioned. The first limitation is the relatively small sample of investigated households. Secondly, sample selection was based on snowball recruitment, which may have led to selection bias.

\section{Conclusion}

The structures of home pharmacies in Novi Sad and Laćarak differ, which implies different healthcare needs. The practice of self-medication was noted both in Novi Sad and Laćarak. While Laćarak residents rely more on the advice of friends and family, Novi Sad residents buy medicines mostly on their own initiative. Medications in both environments are stored properly in the majority of households, but unused medications are mostly disposed of improperly together with household waste. There is a need for education on the proper storage of medication, especially in rural settings, and the development of procedures for proper medication disposal. 


\section{Conflict of interest}

The authors have no conflict of interest to declare.

\section{References}

1. Tomas A, Kusturica MP, Tomić Z, Horvat O, Koprivica DD, Bukumirić D, et al. Self-medication with antibiotics in Serbian households: a case for action? Int J Clin Pharm 2017;39:50713.

2. Aljinović-Vučić V, Trkulja V, Lacković Z. Content of home pharmacies and self-medication practices in households of pharmacy and medical students in Zagreb, Croatia: findings in 2001 with a reference to 1977. Croat Med J 2005;46:74-80.

3. Mölstad S, Lundborg CS, Karlsson AK, Cars O. Antibiotic prescription rates vary markedly between 13 European countries. Scand J Infect Dis 2002;34:366-71.

4. Ministry of Health of the Republic of Serbia. Law on medicinal products and medical devices. Official Gazette of the Republic of Serbia No. 30/2010. 2010;30.

5. Lal A. Pharmaceutical drug promotion: how it is being practiced in India? J Assoc Physicians India 2001;49:266-73.

6. Paut-Kusturica M, Tomić Z, Bukumirić Z, Ninković LJ, Tomas A, Stilinović $N$, et al. Home pharmacies in Serbia: an insight into self-medication practice. Int J Clin Pharm 2015;37:373-8.

7. Kusturica MP, Tomas A, Tomić Z, Bukumirić D, Corac A, Horvat $\mathrm{O}$, et al. Analysis of expired medications in Serbian households. Zdr Varst 2016;55:195-201.

8. Martins AP, Miranda AC, Mendes Z, Soares MA, Ferreira P, Nogueira A. Self-medication in a Portugese urban population: a prevalence study. Pharmacoepidemiol Drug Saf 2002;11: 409-14.

9. Divac N, Jašović-Gašić M, Đukić LJ, Vujnović M, Babić $D$, Bajčetić $M$, et al. Benzodiazepines utilization and selfmedication as correlates of stress in the population of Serbia. Pharmacoepidemiol Drug Saf 2012;13:315-22.

10. Grigoryan L, Burgerhof JG, Degener JE, Deschepper R, Lundborg CS, Monnet DL, et al. Determinants of selfmedication with antibiotics in Europe: the impact of beliefs, country wealth and the healthcare system. J Antimicrob Chemother 2008;61:1172-9.

11. Cameron K. Medication safety in the home: the need for pharmacist involvement. Can Pharm J 2007;140:47-9.
12. Kyingi KS, Lauvo JA. Drugs in the home: danger and waste. World Health Forum 1993;14:381-4.

13. Beirens TM, van Beeck EF, Dekker R, Brug J, Raat H. Unsafe storage of poisons in homes with toddlers. Accid Anal Prev 2006;38:772-6.

14. Franklin RL, Rodgers GB. Unintentional child poisoning treated in United States hospital emergency departments: national estimates of incident cases, population-based poisoning rates, and product involvement. Pediatrics 2008;122: 1244-51.

15. Morgado MP, Morgado SR, Mendes LC, Pereira LJ, CasteloBranco M. Pharmacist interventions to enhance blood pressure control and adherence to antihypertensive therapy: review and meta-analysis. Am J Health Syst Pharm 2011;68:241-53.

16. Abahussain EA, Ball DE. Disposal of unwanted medicines from households in Kuwait. Pharm World Sci 2007;29:368-73.

17. Paut Kusturica M, Sabo A, Tomic Z, Horvat O, Šolak Z. Storage and disposal of unused medications: knowledge, behavior, and attitudes among Serbian people. Int J Clin Pharm 2012; 34:604-10.

18. De Bolle L, Mehuys E, Adriaens E, Remon JP, Van Bortel L, Christiaens T. Home medication cabinets and self-medication: a source of potential health threats? Ann Pharmacother 2008; 42:572-9.

19. Aljinovic-Vucic V, Trkulja V, Lackovic Z. Content of home pharmacies and self-medication practices in households of pharmacy and medical students in Zagreb, Croatia: findings in 2001 with a reference to 1977. Croat Med J 2005;46:74-80.

20. World Health Organization. World report on child injury prevention [monograph on the Internet]. Geneva: WHO; 2008 [cited 2018 Dec 12]. Available from: http://apps.who. int/iris/bitstream/handle/10665/43851/9789241563574_eng. pdf

21. Sanz EJ, Bush PJ, Garcia M, Ahonen R, Almars Dottir AB, Aramburuzabala $\mathrm{P}$, et al. Medicines at home: the contents of medicine cabinets in eight countries. In: Bush PJ, Trakas DJ, Sanz EJ, Wirsing R, Waskilampi T, Prout A, editors. Children, medicines, and culture. New York: Pharmaceutical Product Press; 1996; p.77-104.

22. Boxall $A B$. The environmental side effects of medication. EMBO Rep 2004;5:1110-6. 